\title{
GenNormas: um processo genérico para a Conformidade Legal de Requisitos na Engenharia de Requisitos
}

\author{
Hidelberg Albuquerque ${ }^{1}$, Carla Silva², Danielle Rousy ${ }^{3}$, \\ Márcia Lucena ${ }^{4}$, Gilberto Cysneiros Filho ${ }^{5}$ \\ ${ }^{1}$ Universidade Federal Rural do Pernambuco (UFRPE) - Serra Talhada/PE - Brasil \\ ${ }^{2}$ Universidade Federal de Pernambuco (UFPE) - Recife/PE - Brasil \\ ${ }^{3}$ Universidade Federal da Paraíba (UFPB) - João Pessoa/PB - Brasil \\ ${ }^{4}$ Universidade Federal do Rio Grande do Norte (UFRN) - Natal/RN - Brasil \\ ${ }^{5}$ Universidade Federal Rural do Pernambuco (UFRPE) - Recife/PE - Brasil \\ hidelberg.albuquerquedufrpe.br, ctlls@cin.ufpe.br, \\ danielle@ci.ufpb.br, marciaj@dimap.ufrn.br, g.cysneiros@gmail.com
}

\begin{abstract}
In an organizational environment, products, services and business processes reflect the objectives of the business or the software solution to be developed. Laws are an important source of requirements from the companies, because their non-compliance can result in legal/financial problems. Requirements Engineering seeks to relate requirements and laws, indicating how the laws are going to be operationalized in the software or in the business process activities. In this context, the legal compliance framework Nomos was proposed and it is tailored specifically for the $i^{*}$ modeling language. This work proposes the GenNormas, an adaptation of Nòmos to other requirements languages, such as BPMN, use cases and user stories. Moreover, GenNormas was evaluated in the electronic commerce context.
\end{abstract}

Resumo. Em um ambiente organizacional, os produtos, serviços e processos de negócio refletem os objetivos do negócio ou da solução de software a ser desenvolvida. As leis são uma importante fonte de requisitos exigidos às empresas, pois o seu não-cumprimento pode ocasionar problemas legais/financeiros. A Engenharia de Requisitos busca relacionar requisitos e leis, indicando como as leis serão operacionalizadas no software ou nas atividades do processo de negócio. Neste contexto, o framework de conformidade legal Nòmos foi proposto e é voltado especificamente para a linguagem de modelagem $i^{*}$. Este trabalho propõe GenNormas, uma adaptação do Nòmos para outras linguagens de requisitos, como BPMN, Casos de Uso e User Stories. Além disso, GenNormas foi avaliado no contexto de comércio eletrônico.

\section{Introdução}

As Normas Jurídicas podem ser entendidas como um conjunto de leis ou regras escritas em linguagem natural, que buscam definir os possíveis comportamentos legais aceitos pela sociedade [Lustosa 2001]. Essencialmente, leis são desenvolvidas para a própria sociedade, no sentido de ordenar comportamentos para garantir o equilíbrio e a harmonia da sociedade através da defesa imparcial, social e moral de seus membros. 
Desta forma, as Leis não procuram (ou não devem) beneficiar um indivíduo ou uma relação em particular, mas toda a sociedade [Miranda Rosa 1993].

Em um ambiente organizacional, os produtos e processos de negócio devem ser capazes de refletir os requisitos dos envolvidos no processo (stakeholders), como também os comportamentos esperados nas atividades do negócio ou da solução [Governatori 2010]. Neste contexto, as leis determinam o que é permitido ou requerido para um domínio de atuação, delimitando assim as práticas organizacionais. Leis têm se tornado uma importante fonte de exigência às organizações, sobretudo quando feitas por departamentos governamentais. As empresas devem considerar tais exigências, interpretá-las e determinar como seus produtos e/ou suas práticas de negócio serão afetadas, buscando a observância legal [Schleicher et al 2010]. Em alguns domínios, como àqueles em que se manipulam informações legalmente privadas, o não cumprimento do caráter legal é extremamente delicado, e pode acarretar sérios problemas, tanto no âmbito legal, quanto no financeiro [Governatori 2010].

No ambiente de desenvolvimento de software e na modelagem de processos de negócio, é matéria de estudo da Engenharia de Requisitos a elicitação de requisitos dos stakeholders, do domínio e os requisitos expressos nas leis, entre outros. Por ordem hierárquica, leis tem a predominância de prescrição, direito e execução sobre quaisquer outros requisitos, exigindo modificações destes outros para se adaptarem às exigências legais. A Conformidade Legal de um produto/processo se dá quando há a conciliação entre os requisitos elicitados e o conteúdo legal [Governatori 2010]. Este trabalho refere-se às atividades de Elicitação, Análise e Especificação de Requisitos de Software e Processos de Negócio, de forma a garantir que os requisitos finais estejam de acordo com as legislações relacionadas, satisfazendo também aos stakeholders. Para tanto, as etapas previstas no processo definido no framework Nòmos [Siena 2010] foram analisadas e aplicadas a um exemplo inédito no contexto original - um processo no domínio de comércio eletrônico. Contudo, para utilizar o Nòmos, é preciso o conhecimento técnico de modelagem no framework $i *$ que, por sua vez, não é muito popular na indústria [Carvallo e Franch 2014], o que pode prejudicar a adoção do Nòmos neste meio. Este trabalho propõe-se, portanto, a adaptar o processo proposto pelo Nòmos, deixando-o mais independente do $i^{*}$ e aplicável a outras linguagens de modelagem de requisitos ou de processos de negócio. Usuários de outras linguagens poderão adotar o processo proposto mais facilmente, no intuito de alcançar a Conformidade Legal de seus sistemas de software e/ou processos de negócio.

Este artigo está organizado como segue. A seção 2 apresenta as bases teóricas nas quais apoiamos esta pesquisa, a partir de uma análise dos trabalhos relacionados. A seção 3 descreve a proposta deste trabalho. A seção 4, o exemplo da aplicabilidade da proposta. Finalmente, a seção 5 sintetiza nossa proposta e destaca questões a serem trabalhadas no futuro.

\section{Fundamentação Teórica}

Nas subseções que se seguem serão apresentados (i) o objetivo deste trabalho e a metodologia utilizada, (ii) a pesquisa realizada sobre o tema, (iii) os conceitos do framework Nòmos, modelo-base para nossa abordagem e (iv) a análise dos resultados encontrados na execução deste modelo ao domínio do comércio eletrônico. 


\subsection{Objetivo e Metodologia}

O objetivo geral deste trabalho é adaptar o processo do framework Nòmos, tornando-o menos dependente da linguagem $i^{*}$, buscando alcançar a conformidade legal em especificações de requisitos de software e de processos de negócio, descritas em diversas linguagens de modelagem.

Neste sentido, a primeira atividade realizada foi uma revisão na literatura sobre a influência das regulamentações jurídicas no desenvolvimento de software e de processos de negócio. A segunda etapa envolveu a pesquisa na legislação brasileira para o domínio de comércio eletrônico. Foi executada uma análise da legislação relacionada encontrada no Código de Defesa do Consumidor [Brasil 1990], e na lei brasileira que rege o comércio eletrônico em território nacional [Brasil 2013].

Com base na legislação encontrada, o processo definido no framework Nòmos foi aplicado a um exemplo hipotético no domínio de comércio eletrônico. Como resultado, obteve-se o levantamento de limitações do processo, analisando itens como sistematicidade, abrangência a outros domínios e sua aplicabilidade na indústria.

Baseando-se nas limitações, nossa proposta faz adaptações ao processo original do Nòmos, no intuito de torná-lo independente e aplicável a outras linguagens de modelagem de requisitos. Ratificando a importância do processo original, partes do Nòmos foram mantidas e outras adaptadas. As partes adaptações referem-se principalmente à representação da conformidade legal à outras linguagens de modelagem. Para ilustrar a sua aplicabilidade, aplicamos processo proposto a três linguagens de especificação de requisitos não contempladas no modelo original do Nòmos: a Notação para Modelagem de Processos de Negócios (BPMN), os Diagramas de Casos de Uso da UML, e a técnica ágil User Story. Para dar suporte a conformidade legal, foram propostas extensões para estas linguagens, sempre visando causar o mínimo de impacto de modo a não inviabilizar o uso das respectivas ferramentas CASE.

\subsection{Trabalhos Relacionados}

Na busca de uma solução para a necessidade da observância legal de requisitos e processos de negócio, foram feitas pesquisas na literatura relacionada. Assim, alguns trabalhos chamaram a atenção sobre este tema, os quais são listados a seguir.

Schleicher et al (2010), apresenta o conceito teórico de escopo de conformidade para restringir o comportamento crítico de determinados grupos de stakeholders dentro de um processo de negócio, modelando estes escopos com a Notação BPMN. A análise dos requisitos é feita manualmente por um consultor, responsável por determinar requisitos críticos, e se, como e onde estes requisitos serão aplicados. Contudo, não foram explicitadas as diretrizes para a análise legal, nem como estes escopos influenciam os casos alternativos de prescrição legal. O caráter mais delicado desta abordagem, do nosso ponto de vista, baseia-se na premissa de que ao limitar as decisões dos stakeholders através de um consultor, o sucesso do projeto pode ser ameaçado.

Siena (2010) estende os conceitos organizacionais da linguagem $i^{*}$ [Yu 1995], apresentando o framework Nòmos como uma solução lógico-conceitual para alcançar o caráter da conformidade legal de requisitos. Uma limitação do Nòmos reside no forte acoplamento aos modelos $i^{*}$, exigindo o conhecimento prévio desta linguagem, além da sua falta de popularidade na indústria, o que pode dificultar na sua adoção. Ingolfo et al AlbUQUeRQUe, H.; SILVA, C.; ROUSY, D.; LUCENA, M.; FILHO, G. C.

GenNormas: um processo genérico para a Conformidade Legal de Requisitos na Engenharia de Requisitos isys | Revista Brasileira de Sistemas de Informação, Rio de Janeiro, vol. 9, No. 4, pp. 57-76, 2016 
(2013) estende o trabalho de Siena (2010), no contexto da camada de argumentação, com uma proposta de suporte à tomada de decisão. Em outro trabalho, Ingolfo et al (2014) estende outra vez o framework Nòmos, abstraindo os conceitos de papéis, normas e situações legais como relacionamentos sociais. Apesar deste forte acoplamento existente no framework Nòmos e o $i^{*}$, o processo apresentou-se coeso o suficiente para ser adaptado e utilizado como um padrão para alcançar a conformidade legal de requisitos de software, aplicáveis também a processos de negócio.

O trabalho apresentado por Gordon e Breaux (2011) busca elicitar os requisitos legais a partir da busca por leis similares em diferentes jurisdições, através de um processo automatizado. Em seguida, os resultados dos textos legais são traduzidos para a linguagem natural, buscando atender a múltiplas jurisdições, conservando a rastreabilidade. As leis levantadas são contrapostas comparando-se as condições para sua aplicabilidade, até chegar a um consenso. Este trabalho apresenta potencial para a análise de requisitos legais, porém, não deixa claro: quais são as diretrizes utilizadas para elicitação e análise do conteúdo legal, como é executada a automação, não considerando os impactos reais de casos da jurisprudência no projeto.

Ghavanati (2013) também apresenta uma abordagem orientada a objetivos, baseada na linguagem URN (User Requirements Notation), para descrever e combinar a legalidade dos modelos organizacionais, utilizando os conceitos da Engenharia de Requisitos Orientada a Objetivos. O autor propõe a adoção de única linguagem para a modelagem dos processos, a realização de objetivos, a análise legal e para busca da conformidade legal. Assim como o framework Nómos, este trabalho utiliza as bases legais encontradas em Hohfeld (1913), fornecendo uma metodologia para manuseio e análise de várias regulamentações. Contudo, julgamos o framework Nòmos mais simples de ser usado, tornando-o melhor candidato à nossa proposta.

\subsection{O Framework Nòmos}

Buscando uma solução para o problema da conformidade legal dos requisitos, Siena (2010) desenvolveu uma solução lógico-conceitual, baseada na argumentação e refinamento dos requisitos dos stakeholders, a partir das exigências legais impostas ao domínio relacionado. O Framewok Nòmos pode ser entendido como uma linguagem de modelagem de requisitos legais, fundamentada nos conceitos da Engenharia de Requisitos Orientada à Objetivos.

Em linhas gerais, o framework Nòmos propõe que a elicitação dos requisitos dos stakeholders sejam inicialmente levantados e representados utilizando o framework $i^{*}$, seguidas das análises do impacto legal nestes requisitos. Em seguida, são executadas etapas de checagem e modelagem destes requisitos do ponto de vista legal, concluindo com a geração de uma solução compatível às duas realidades citadas. $\mathrm{O}$ processo proposto por Siena (2010) visa garantir que as propriedades de cumprimento e conformidade legais estejam presentes no modelo final. Para este fim, o processo é dividido em três fases lógicas, como será explicitado posteriormente, compondo um processo sistemático e claro. O resultado final é a geração de um modelo de requisitos que represente um conjunto de Requisitos de Conformidade, resultado da sincronização dos requisitos do negócio às leis, não podendo existir elementos que bidireccionalmente os contraponha. 
Nòmos foca sua análise no ambiente organizacional onde sistema/processo será inserido, capturando seus relacionamentos sociais/intencionais. Com o Nòmos é possível obter um melhor entendimento do problema em estudo, das razões que envolvem as tomadas de decisão e a descrição de potenciais alternativas para satisfação dos requisitos, conceitos herdados da linguagem $i^{*}$ [Yu 1995]. Para ilustrar Nòmos e a nossa proposta, especificamos um processo de negócio e capturamos os requisitos de um software de apoio a este processo no domínio de comércio eletrônico (e-Commerce).

Para uma análise mais efetiva sobre o impacto legal nos requisitos, é preciso ter conhecimento sobre a natureza das relações jurídicas. Para tanto, serão apresentados os conceitos e modelos, que também servirão de base para a nossa proposta. Os princípios legais utilizados por Nòmos são baseados na Taxonomia Hofeldiana [Hohfeld 1913], que enxerga as relações jurídicas como relacionamentos de interdependência entre sujeitos. Hohfeld (1913) remodela os conceitos de direito e dever em quatro pares, que devem ser analisados em conjunto, para o entendimento dos conceitos legais. Mesmo correlacionados em pares, para o entendimento adequado, é preciso o conhecimento dos demais pares. São eles:

- Direito-Dever (Claim-Duty): no sentido de dar precisão a esta relação, Hohfeld (1913) correlaciona estes conceitos a partir da premissa de que todo "direito" exige um "dever". A afirmativa "um sujeito X tem um dever para com o sujeito Y", significa dizer que $\mathrm{X}$ é obrigado a executar alguma ação em favor de Y; por sua vez, o sujeito $\mathrm{Y}$ tem um direito em relação à $\mathrm{X}$. Ter um "direito em relação a outrem" significa a existência de um direito à reinvindicação: ou seja, de estar numa posição privilegiada de exigir o cumprimento de um dever de outrem.

- Privilégio-“Não-Direito" (Privilege-NoClaim): uma vez admitido que o "direito" é uma posição legal que exige o cumprimento do "dever" de outro indivíduo, privilégios são liberdades comportamentais, estando outros indivíduos impossibilitados de exigirem executarem ações legais para impedi-las ou negá-las. Privilégio é, pois, uma liberdade que um sujeito $\mathrm{X}$ possui para agir (ou não) em favor de um sujeito $\mathrm{Y}$; por sua vez, $\mathrm{Y}$ não possui o direito (ou possui o "nãodireito") de reivindicar qualquer ato de X. Todavia, um privilégio existe desde que não haja a violação dos direitos de outros indivíduos.

- Poder-Responsabilidade (Power-Liability): o conceito de "poder" está ligado a habilidade de fazer algo ou ter a competência para executar uma ação. $\mathrm{Na}$ Taxonomia Hohfeldiana, o poder é a expressão da vontade de um indivíduo que predomina sobre a vontade de outros, modificando a relação jurídica entre eles. A parte submissa tem a responsabilidade de executar o que lhe for estabelecido por seu dominante. Esta relação pode ser observada, por exemplo, quando do nãocumprimento de um dever de $\mathrm{X}$ para com $\mathrm{Y}$, tendo este último reivindicado seu direito diante de um tribunal. Na relação de poder, o exercício do direito de Y pode ser desempenhando a qualquer momento, estando a parte submissa sujeita a executar o que lhe for estabelecido. $O$ indivíduo subordinado $X$ tem a responsabilidade de executar as ações do sujeito detentor do poder. Somente a Autoridade Legal é responsável por autenticar esta relação.

- Imunidade-Incapacidade (Immunity-Disability): a imunidade pode ser entendida como a capacidade que um indivíduo possui de não sofrer o controle de outros AlbUQUeRQUe, H.; SILVA, C.; ROUSY, D.; LUCENA, M.; FILHO, G. C.

GenNormas: um processo genérico para a Conformidade Legal de Requisitos na Engenharia de Requisitos isys | Revista Brasileira de Sistemas de Informação, Rio de Janeiro, vol. 9, No. 4, pp. 57-76, 2016 
indivíduos, através da prova de sua incapacidade legal. De uma maneira mais prática: se um sujeito $\mathrm{X}$ apresentar provas de que é incapaz de cumprir uma ação judicial, ele está imune e desobrigado nesta relação. Por sua vez, diante desta atestação da incapacidade de $\mathrm{X}$, o sujeito $\mathrm{Y}$ não pode exigir o cumprimento da ação. Igualmente, somente uma Autoridade Legal poderá atestar e autenticar esta relação.

Em seu trabalho, Siena (2010) faz a representação das leis relacionadas ao projeto utilizando-se do modelo jurídico de Proposição Normativa (Normative Proposition - NP), como sentenças que expressam a responsabilidade de indivíduos sob a conformidade legal, com relação a um objeto, relacionando leis comuns. As NPs são utilizadas no entendimento das prescrições e declarações legais dentro do domínio do problema, e como estas influenciam na definição de requisitos. Visualmente, Nòmos representa estes conceitos de dependência entre sujeitos, adaptando o modelo de dependência estratégica do $i$, sendo os indivíduos legais representados como atores em os pares de conceitos legais, como demonstrado na Figura 1a [Siena 2010]. A Figura 1b apresenta um modelo parcial de dependências legais e relações de dominância para o domínio do comércio eletrônico [Albuquerque et al 2014a].

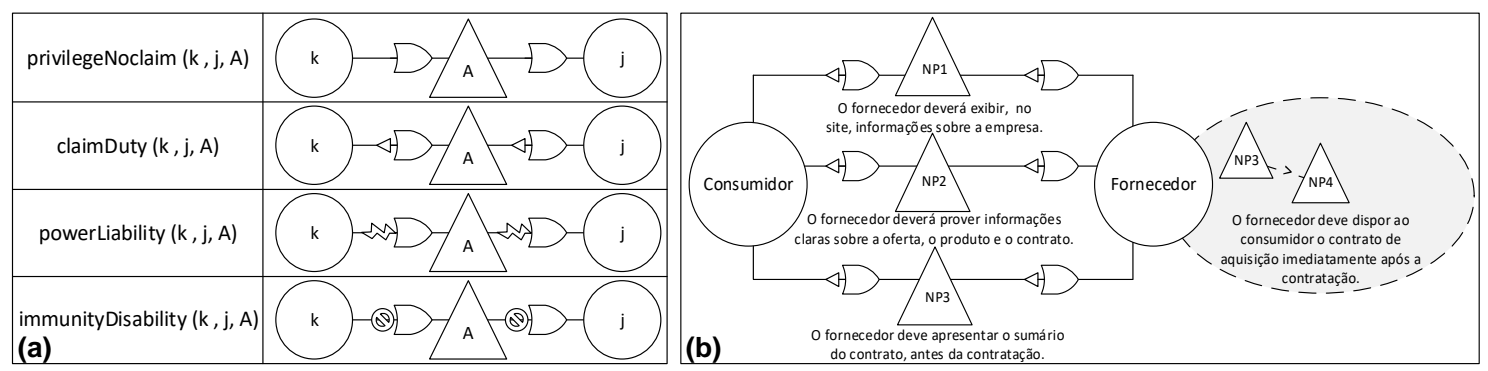

Figura 1. Representação das Relações Legais em Nòmos

\subsubsection{O Processo do Nòmos}

A primeira fase do processo (Elicitação de Requisitos) é subdividida em duas etapas: Elicitação dos Requisitos dos Stakeholders e Levantamento Legal. A primeira etapa se dá pelo levantamento dos requisitos dos stakeholders, utilizando quaisquer técnicas de elicitação. A segunda etapa envolve a busca por legislações que estejam relacionadas ao campo de atuação da organização, ou ao domínio da solução a ser desenvolvida. $\mathrm{O}$ entendimento e interpretação do conteúdo legal são complexos, devido a fatores como falta de padronização dos textos legais, referências cruzadas, entre outros, tornando-os suscetíveis a alterações futuras [Ghanavati 2013]. Ingolfo et al (2013), recomenda que esta etapa de seleção legal deve ser executada por especialistas do direito, que deverão usar como critério a relação entre o conteúdo legal e sua aplicabilidade no domínio.

$\mathrm{Na}$ segunda fase do processo (Modelagem de Requisitos), os requisitos e as leis são analisadas do ponto de vista da conformidade legal, utilizando quatro etapas de modelagem: (i) Personificação de Sujeitos Legais, (ii) Identificação de Alternativas Legais, (iii) Busca por Realizações e (iv) Identificação de Artefatos de Prova. A etapa de Personificação de Sujeitos Legais busca correlacionar os atores dos requisitos e os sujeitos legais. Se identificada a relação, o ator do domínio passa a ser considerado um sujeito legal, com seus direitos e deveres. Outros atores que não foram relacionados, mas que podem ter relevância no processo em ambos os contextos (legal e requisitos), 
pode estar presente no modelo. Uma vez feita esta identificação, é executada a etapa de Identificação de Alternativas Legais, procurando identificar cenários legais alternativos e as relações de dominância entre estes cenários. Estas relações de dominância são descritas pela expressão "NPy > NPx", onde, sob determinadas circunstâncias, o cumprimento de um cenário ou lei não confronta a outra, e a execução de quaisquer das alternativas torna válida uma relação de conformidade. A etapa de Busca por Realizações executa a análise dos elementos comportamentais dos atores, comparando-os com os comportamentos permitidos na lei. Para que o ator possa alcançar a conformidade legal, ele deve atender dois critérios [Ingolfo et al 2013]: Prova de Cumprimento e Prova de Conformidade. Assim, requisitos que não se enquadrem nestas condições deverão ser refinados, modificados ou eliminados, ou adicionados os requisitos, para que se estabeleça a conformidade esperada. Na etapa de Busca por Realizações são executados os refinamentos dos requisitos legais (expressos na linguagem $i^{*}$ ) para identificação e execução de tarefas. Por fim, última etapa desta fase, na Identificação de Artefatos de Prova procura-se localizar e/ou inserir recursos para provar que o processo/produto está em Conformidade Legal.

A última fase do processo (Verificação da Conformidade Legal) prevê a verificação de todos os requisitos que foram refinados, das leis relacionadas, dos documentos gerados, se estes atendem à conformidade legal esperada e se os documentos gerados não fogem ao modelo proposto. Caso sejam encontradas inconsistências, a modelagem deverá ser refeita. Quando não houver mais modificações a serem executadas, o processo é finalizado.

Sob nossa análise, o processo apresentado pelo Nòmos demonstrou-se ser sistemático para ser utilizado como um padrão para alcançar a Conformidade Legal. Contudo, pensamos ser necessário aplicar o Nòmos a outros domínios, para verificar sua aplicabilidade fora de seu escopo original. Foi escolhido o domínio do comércio eletrônico. A decisão pela escolha deste domínio se deu a partir de três fatores: (i) evidenciação do aumento das transações comerciais pela Internet na América Latina, particularmente no Brasil [Visa 2014] [e-Bit/Buscapé 2013], (ii) o crescimento do número de reclamações relacionadas às transgressões de direitos dos consumidores online brasileiros [Sampaio e Hildsorf 2012], e (iii) a promulgação da Lei Brasileira que rege o comércio eletrônico em Território Nacional [Brasil 2013].

Devido ao escopo deste documento, o cenário de requisitos e de leis foi reduzido. As exigências legais foram capturadas pelos fragmentos de lei, encontrados em Brasil (2013), e aplicados ao exemplo: os fragmentos de lei selecionados exigem determinadas obrigações que os site de compras on-line devem cumprir para com o clientes, e foram representadas na Figura 1b. Por sua vez, a Figura 2 mostra uma representação parcial do modelo de requisitos de conformidade gerado em Nòmos, para o domínio do e-Commerce: (i) os fragmentos de lei prescrevem obrigações que os sites devem que cumprir em benefício dos clientes; (ii) as proposições normativas são representadas tanto externa quanto internamente à fronteira dos atores, para expressar a dependência legal (externa) e demonstrar como o ator será realizada a exigência jurídica (interna). A geração do modelo apresentado na Figura 2 deverá permitir uma visualização completa de todas as etapas de modelagem executada.

AlbuQuerque, H.; SILVA, C.; ROUSY, D.; LUCENA, M.; FILHO, G. C. 




Figura 2. Modelo parcial dos Requisitos de Conformidade, utilizando Nòmos.

\subsection{Resultados encontrados}

Ao aplicar o framework Nòmos à um novo domínio, procuramos identificar limitações na sistematicidade e clareza no processo. Observou-se que o processo original não necessitou de extensões ou modificações. Além disso, sua execução foi bem sucedida no que diz respeito a sua aplicabilidade a um novo domínio. Originalmente, o processo foi aplicado no domínio de sistemas hospitalares [Siena 2010] e neste trabalho foi aplicado ao domínio do e-Commerce. Destacamos, portanto, que o processo Nòmos apresenta-se claro e sistemático, aplicável a pelo menos um novo domínio.

Por outro lado, por ser o Nòmos uma extensão da linguagem $i *$ [Yu 1995], é perceptível o forte acoplamento entre os modelos destes dois frameworks, exigindo do profissional que deseje utilizar o Nòmos o conhecimento prévio do $i^{*}$. E apesar do entendimento proporcionado pelo $i^{*}$ (cenários, agentes, responsabilidades e relacionamentos), esta linguagem não é muito popular na indústria [Yu et al 2013] [Carvallo e Franch 2014]; como consequência, a adoção do Nòmos na indústria pode ser prejudicada. Após a aplicação do processo e reconhecendo os benefícios apresentados pelo Nòmos, observamos que seria possível adaptá-lo para torná-lo mais independente do $i^{*}$ (limitação identificada), para torná-lo aplicável a outras linguagens. Assim, profissionais adeptos de outras linguagens de modelagem poderiam adotar o processo adaptado mais facilmente, promovendo a popularização de um processo para alcançar a conformidade legal de requisitos de software ou de processos de negócio. O próximo capítulo apresenta o processo adaptado, chamado de GenNormas - Um Processo Genérico para Conformidade Legal na Engenharia de Requisitos.

\section{O GenNormas}

Nossa proposta é uma adaptação do processo do Nòmos para definir um processo genérico, independente de linguagem de modelagem de requisitos. Focamos nosso trabalho na Engenharia de Requisitos por reconhecermos sua importância na 
identificação e compreensão das dimensões de um problema que se quer solucionar (inclusive às de conformidade legal), e na busca de respostas. Além disso, entendemos que se uma solução especificada está em conformidade legal com as normas do seu domínio, estas também serão respeitadas nas demais fases de desenvolvimento.

Reconhecendo a eficácia do framework Nòmos, apresentamos uma adaptação do seu processo, no intuito de torná-lo aplicável a especificações de requisitos descritas em outras notações de modelagem diferentes do $i^{*}$. Nossa proposta, batizada inicialmente de Nòmos Genérico (ou GenNòmos), objetiva tornar maior o alcance do Nòmos, sem, contudo, perder os seus benefícios [Albuquerque et al 2014a]. Posteriormente, o processo foi renomeado para GenNormas (já que o termo Nòmos significa "norma" no grego), para não corrermos o risco de apropriação indevida do nome do framework original. Para esta adaptação, elegemos partes do processo original que não foram alteradas e outras que devem ser adaptadas à linguagem de modelagem escolhida.

A opção de propor um processo genérico é baseada em dois motivos: por valorizarmos o papel dos stakeholders no levantamento de requisitos de um produto ou processo de negócio, por serem estes agentes os responsáveis pela aceitabilidade dos requisitos do processo/produto pretendido. Para tanto, faz necessário o uso de técnicas de modelagem que facilitem o entendimento de usuários desacostumados à leitura técnica. Em segundo lugar, pensando nos analistas de negócios e profissionais de requisitos, e entendendo que, ao limitar estes profissionais a utilização de uma única linguagem de modelagem, corre-se o risco de prejudicar o desenvolvimento da solução devido a profissionais não-habilitados na linguagem especificada, o que poderia causar incorretude de requisitos e/ou aumento de custos, entre outros fatores.

No intuito de alcançar a conformidade legal de requisitos, o processo GenNormas mantêm a divisão em 3 macrofases: Elicitação de Requisitos, Processo de Modelagem e Verificação de Conformidade. Para atingir este objetivo, cada macrofase deve executar determinadas tarefas coordenadas. Ao fim de cada fase, são gerados os documentos que servirão de base para a análise e execução da etapa seguinte, até à finalização do processo. De maneira geral, as macrofases buscam: (i) elicitar os requisitos dos stakeholders e as leis relacionadas ao domínio, (b) analisar e modelar os requisitos dos stakeholders do ponto de vista legal, e; (iii) executar testes de aceitabilidade dos requisitos modelados, além da verificação dos os artefatos gerados. Uma vez aceita a solução, o processo é finalizado. Caso contrário, o processo de modelagem é reiniciado, até que haja um consenso.

É mister destacar que todas as etapas previstas na proposta original são essencialmente discursivas, entre analistas e os stakeholders [Ingolfo et al 2013]. Esta prática objetiva facilitar a comunicação entre os envolvidos no processo. Concordando com a relevância deste fator, sugerimos a mesma orientação. Todavia, não se exclui a possibilidade de, em trabalhos futuros, utilizar-se de técnicas automatizadas para orientar e facilitar o processo de aceitabilidade dos requisitos, ou pela seleção de leis no processo. Logicamente, para que o GenNormas seja executado, é imperativa a existência de Leis que regulem ou o domínio da aplicação, ou prática do negócio analisado, ou ainda os requisitos dos stakeholders. 


\subsection{O processo do GenNormas}

\subsubsection{Fase 1: Elicitação de Requisitos}

A fase de elicitação de requisitos divide-se em duas etapas: (1) Elicitação dos Requisitos dos Stakeholders e (2) Elicitação de Normas ou Leis, e poderão ser feitas por profissionais distintos: os engenheiros de requisitos e os especialistas no direito. Desta forma, as etapas desta fase podem ser executadas paralelamente, se preferível.

A etapa de Elicitação de Requisitos dos Stakeholders compreende a elicitação de requisitos do sistema/processo junto aos stakeholders. Esta etapa praticamente não foi modificada no processo original, exceto que os analistas são livres para decidir quais técnicas de elicitação e modelagem de requisitos serão utilizadas. No Nòmos, esta etapa também poderia ser executada utilizando qualquer paradigma de coleta de requisitos. Contudo, o documento de requisitos deveria ser invariavelmente gerado (ou convertido) na linguagem $i^{*}$. Ao final desta etapa, deverão ser produzidos os artefatos necessários que expressem os requisitos do produto ou do processo de negócio, para a próxima fase.

A segunda etapa desta fase é a Elicitação de Normas ou Leis. No GenNormas, propomos a junção da etapa "Identificação de Alternativas Legais" (no processo original, existente na etapa de modelagem) a esta etapa. Assim, deverão ser mapeadas as leis no formato de NPs, e definidas as relações de dominância entre elas. Em virtude da dificuldade de entendimento legal nos textos legais e da necessidade de utilização de especialistas do direito, optamos por reunir todas as atividades de análise e manipulação legal para uma única etapa. Agindo assim, a consultoria aos especialistas legais poderá ser feita, sob demanda, o que acarretará diminuição de custos. No GenNormas, esta etapa compreende três atividades, conforme explicado a seguir:

(i) Seleção de Leis: As atividades aqui executadas objetivam: selecionar e acompanhar as leis relacionadas ao domínio, identificar as partes relevantes para o projeto em questão. Preferencialmente estes procedimentos, executados por especialistas, deverão selecionar as leis a partir de fatores como: entendimento do domínio, legislações relacionadas ao contexto, análise das diferentes jurisdições, identificação de padrões comportamentais, e representação na Taxonomia Hohfeldiana, além de pesquisas pela jurisprudência.

(ii) Mapeamentos das Leis: esta atividade se propõe a mapear os fragmentos de leis e dos atores selecionados, utilizando o formato de Proposição Normativa (NP). Uma vez que uma NP pode representar a junção de fragmentos de leis, não necessariamente presentes num mesmo documento, propomos a documentação destas NPs utilizando o Modelo NPx (Tabela 1), [Albuquerque et al 2014a, adaptado]. Neste mapeamento, deverão ser identificados e estabelecidos os cenários alternativos de prescrição legal, especificando visualmente e textualmente as relações de dominância entre eles.

É necessário fazer a análise pelo tipo de Tomada de Decisão correspondente à Conformidade Legal desejada, e aos riscos de seu cumprimento. Os critérios para esta análise permanecem inalterados do Nòmos: (i) Tomada de Decisão baseada em Precaução (esforço de cumprir todos os deveres), (ii) Tomada de Decisão Oportunista (todas as alternativas são aceitáveis, incluindo as que podem violar a lei), (iii) Tomada de Decisão propensa a Risco (realização dos deveres mínimos) e (iv) Tomada de 
Decisão de Alta Conformidade (cada prescrição é considerada, mesmo que não seja necessária).

Tabela 1. Modelo de representação NPx: elementos da proposição normativa

\begin{tabular}{|c|c|}
\hline \multicolumn{2}{|r|}{$\begin{aligned} \mathrm{NPx}= & \{\text { Ator }, \text { Contraparte }, \text { TipoDireito }, \text { Ação }, \\
& \text { BaseLegal }, \text { Jurisdição, }, \text { Relação de Dominância }\}\end{aligned}$} \\
\hline$N P x$ & identificação da proposição normativa. \\
\hline Ator & sujeito passivo da ação (quem se obriga o cumprimento legal) \\
\hline Contraparte & sujeito ativo da ação (quem a lei beneficia e pode reinvidicar o direito). \\
\hline TipoDireito & declaração do tipo de direito especificado, segundo Hohfeld (1913). \\
\hline$A c ̧ \tilde{a} o$ & a ação/comportamento que deve ser executado no processo/produto. \\
\hline BaseLegal & identificação do fundamento jurídico (rastreabilidade). \\
\hline Jurisdição & jurisdição onde as bases legais são aplicáveis. \\
\hline $\begin{array}{l}\text { Relação de } \\
\text { Dominância }\end{array}$ & relação de dominância à qual está sujeita, se aplicável. \\
\hline
\end{tabular}

Para facilitar a visualização e o entendimento destas relações legais, junto ao modelo de especificação NPx, em nossa proposta conservamos a mesma representação gráfica das leis e suas relações de dependência entre os sujeitos legais (Figura 1b).

Ao final desta etapa, deverão ser gerados: (i) o modelo NPx e suas especificações; (ii) a representação gráfica dos relacionamentos e dependência entre os sujeitos legais, e; (iii) um documento formal, elaborado pelos especialistas de requisitos, que comprove a autorização dos stakeholders sobre a tomada de decisão escolhida. Esses artefatos servirão de alicerce para o restante do processo, como será apresentado.

\subsubsection{Fase 2: Processo de Modelagem}

As fases referentes ao processo de modelagem devem ser executadas do intuito de fazer a representação e o refinamento dos requisitos elicitados. De fato, leis e requisitos podem ser conflitantes, e como as leis não podem ser alteradas pelos analistas de negócio, será exigido destes profissionais a adequação e o refinamento dos requisitos. Esta modelagem deverá acontecer a partir da interpretação legal e da forma como o processo será mapeado, a partir da negociação entre profissionais de requisitos, especialistas do direito e stakeholders. Esta fase de modelagem deve receber como parâmetros de entrada os documentos de requisitos e o mapeamento legal, oriundos da fase anterior. Para executar a modelagem, esta fase foi dividida em quatro etapas.

Na primeira etapa, Personificação de Sujeitos Legais, deverão ser relacionados os sujeitos legais identificados nas NPs, e os atores do processo do negócio. O estabelecimento deste relacionamento é crucial para identificar no processo como o sujeito legal será considerado. O processo de identificação deste relacionamento poderá ser feito explicitamente (por nome) ou implicitamente (por comportamentos comuns). Enfatizamos a necessidade de uma representação textual/visual no modelo de requisitos que será aplicado, para facilitar a visualização principalmente para usuários não acostumados à leitura técnica (a título de exemplo, a Figura 2 demonstra este ALbUQUeRQUe, H.; SILVA, C.; ROUSY, D.; LUCENA, M.; FILHO, G. C.

GenNormas: um processo genérico para a Conformidade Legal de Requisitos na Engenharia de Requisitos isys | Revista Brasileira de Sistemas de Informação, Rio de Janeiro, vol. 9, No. 4, pp. 57-76, 2016 
relacionamento no modelo $i^{*}$ ). Uma vez identificada estas relações, os atores do processo que mantêm um relacionamento de personificação serão considerados como os sujeitos legais, com os mesmo direitos e deveres. Outros atores relevantes do processo que não possuam identificação com nenhum sujeito legal podem permanecer no processo, mas sem participação em relação de personificação.

Na etapa da Busca por Realizações (assim como no Nòmos original), todos os comportamentos, objetivos ou atividades dos requisitos deverão ser colocados à prova do comportamento legal expressos nas NPs. As atividades desta etapa buscam assegurar que as leis mapeadas estejam integradas às atividades do processo/produto. Para tanto, é preciso identificar os casos de realização nos requisitos para as ações esperadas pelas NPs, selecionar os casos de riscos de não-conformidade e priorizar seu cumprimento. Além disso, é preciso descobrir possíveis conflitos existentes entre requisitos e NPs e resolvê-los. Para verificar a existência da relação de realização, todas as NPs e todos os elementos comportamentais dos sujeitos legais deverão ser analisados, buscando identificar nos sujeitos legais os comportamentos que contribuem para a realização de cada NP. Para tanto, deverão ser analisados os seguintes casos [Siena 2010]:

- Caso 1: todos os elementos comportamentais deverão ser analisados em face à NP analisada, para verificar se existem comportamentos contrários à ação legal esperada. Se existirem, na nossa proposta consideramos estes casos um risco imediato, e estes elementos devem ser refinados ou, se necessário, excluídos.

- Caso 2: se não for encontrado nenhum elemento que realize a NP (risco grave), novos elementos comportamentais devem ser inseridos nas atividades do sujeito legal responsável por realizá-la, relacionando o(s) elemento(s) com a NP.

- Caso 3: se encontrado algum elemento que realize a NP direta e integralmente, este elemento deve ser relacionado em realização com a NP.

- Caso 4: se encontrado algum elemento que realize parcialmente a NP analisada (risco leve), este elemento deverá ser refinado para que a realização plena possa existir. Uma vez refinado, o elemento em questão participa da relação de realização.

- Caso 5: sempre que for estabelecida uma relação de realização, todos os demais elementos do ator devem ser reanalisados, para verificar (i) se existe algum elemento que se contraponha a relação de realização assinalada; (ii) se há algum elemento que afete a relação de realização assinalada, e (iii) se nenhum elemento não será afetado pela nova relação de realização. Em quaisquer dos casos, ou o elemento que afeta a realização, ou o elemento que é afetado, ou ainda a própria relação de realização deverá ser revista e, se necessário, os elementos/relação deverão ser refinados.

Assim como no Nòmos, destacamos que, quando surgirem riscos na realização de alguma NP, estes deverão ser solucionados imediatamente. Caso o risco não seja sanado pelos analistas, tal situação deverá ser levada ao stakeholder, para que seja determinada a realização. Esta etapa iterativa só será concluída quando todas as NPs forem realizadas e os riscos forem eliminados. Assumimos aqui integralmente as diretrizes propostas por Siena (2010) e enfatizadas por Ingolfo et al. (2013), para a certificação da conformidade legal nas relações de realização: (i) Prova de Cumprimento, que determina que para cada NP do processo deve existir pelo menos AlbUQUeRQUe, H.; SILVA, C.; ROUSY, D.; LUCENA, M.; FILHO, G. C. 
um elemento que a realize, ou que esteja numa relação de dominância com elemento realizado, e (ii) a Prova de Conformidade, quando não deve haver nenhum elemento em irregular à NP, seja por violação ou afetação. Se estes dois critérios forem atendidos, a Conformidade Legal é garantida. Os analistas de negócio ou engenheiros de requisitos são livres para utilizarem quaisquer técnicas de negociação de requisitos com os stakeholders. Destacamos ainda, a necessidade de uma representação gráfica clara das relações de realização das NPs, no modelo de requisitos escolhido.

Originalmente a etapa de Operacionalização de Realizações no Nòmos, prevê o refinamento dos objetivos em tarefas no modelo $i *$. Em alguns modelos de requisitos, a representação comportamental é feita diretamente na forma de tarefas, como a Notação BPMN [OMG 2010]. No GenNormas esta etapa possa ser omitida ou readaptada, conforme o caso, a partir da análise do modelo utilizado: se na linguagem de modelagem escolhida, as atividades forem representadas por modelos comportamentais de baixo nível (como tarefas, presentes no $i *$ ou BPMN), a realização das NPs deve ser executada diretamente com as tarefas que as realizam, omitindo-se esta etapa.

Sobre a etapa de Identificação de Artefatos de Prova: os documentos gerados durante a especificação dos requisitos podem ser utilizados como prova de que o produto/processo foi projetado observando o caráter legal. O Magistrado é responsável por avaliar esta auditabilidade legal [Ghanavati 2013]. Contudo, não lhes é exigido o conhecimento técnico sobre modelagem de requisitos de software ou de processos de negócio, importando efetivamente a execução em tempo real. Nòmos recomenda que devam existir no projeto, recursos que sirvam como Artefatos de Prova da conformidade legal. Os analistas de requisitos devem fazer uso destes recursos, certificando-se de destacá-los visualmente, para que sejam implantados na solução/processo.

Ao final desta fase de modelagem, deverá ser gerado o "Documento Provisório de Especificação de Requisitos de Conformidade". A temporariedade deste documento refere-se à necessidade de verificação posterior dos artefatos e da solução. Junto deste documento também serão encaminhados para a fase posterior os artefatos de Mapeamento Legal, que foram herdados anteriormente.

\subsubsection{Fase 3: Verificação de Conformidade}

Esta fase de verificação objetiva (i) validar se os requisitos de conformidade atendem aos critérios de Conformidade e Cumprimento Legais exigidos, (ii) se os requisitos são aceitos pelos stakeholders, e (iii) se os artefatos gerados estão em conformidade com o processo (buscando discrepâncias). Esta verificação de aceitabilidade de requisitos e artefatos é uma das atividades previstas na Engenharia de Requisitos.

Para a verificação e determinação da Conformidade Legal Final dos Requisitos, deverão ser consideradas (i) as especificidades do projeto/ domínio, assegurando que os requisitos legais foram integrados à especificação, (ii) que os requisitos dos stakeholders foram respeitados, (iii) que possíveis riscos foram corrigidos, e (iv) que os artefatos produzidos estão em conformidade com o processo e a linguagem de modelagem utilizada. Dessa forma, os profissionais de requisitos e analistas de negócio são responsáveis por autenticar a veracidade e conformidade dos artefatos ao processo/linguagem utilizada. Os stakeholders são responsáveis aceitar os requisitos finais: se algum requisito ou artefato não for aceito, o processo deverá retornar para a 
fase de modelagem, para serem reajustados. Alertamos para o fato de que, quanto maior a probabilidade de alteração de requisitos, ou inclusão de novos elementos ao projeto, corre-se risco de que todo o processo seja revisitado. Ao final desta etapa, quando não houver mais modificações, a iteração acaba e o processo é finalizado.

\section{Aplicação do GenNormas à um exemplo de Comércio Eletrônico}

Para demonstrar a aplicabilidade da nossa proposta, optamos por utilizar o domínio do comércio eletrônico utilizando os mesmos parâmetros legais empregados no Nòmos. Aplicamos nossa proposta em três técnicas de especificação de requisitos diferentes: a Notação para Modelagem de Processo de Negócio (BPMN) [OMG 2011], o Diagrama de Casos de Uso da UML [OMG 2010] e a técnica ágil de Estórias do Usuário (User Story) [Cohn 2004]. A escolha destas técnicas foi motivada por sua popularidade na indústria e na academia, e por permitirem um entendimento do problema num alto nível de abstração. As alterações sugeridas visam causar o mínimo de impacto em suas notações originais e no uso de ferramentas CASE destas técnicas,

A Notação BPMN é capaz de fornecer a compreensão das etapas e dos procedimentos internos de um processo de negócio, utilizando uma notação clara, representando os processos de trabalho como atividades a serem executadas, em um método ordenado de fluxos de ações, consumo/produção de recursos e comunicação de dados [OMG 2011]. Uma proposta inicial de adaptação do Nòmos em BPMN pode ser encontrada em Albuquerque et al (2014b). A Figura 3 apresenta um modelo parcial de requisitos (somente a parte do sistema) para o domínio do comércio eletrônico.

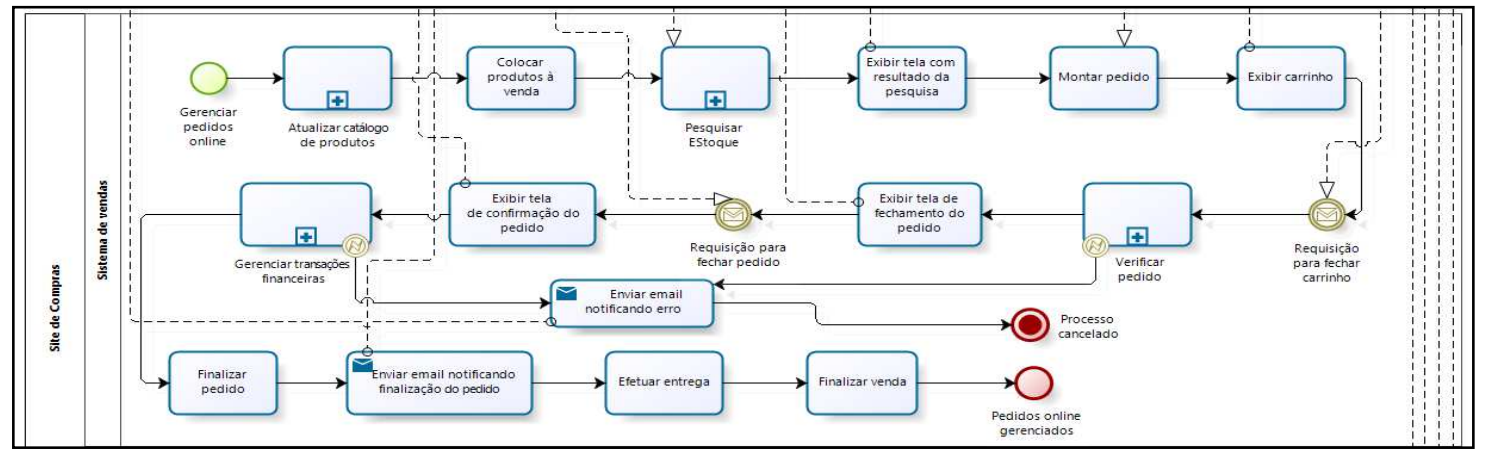

Figura 3. BPD de Requisitos para o domínio do comércio eletrônico (adaptado [Albuquerque et al 2014b])

O Diagrama de Caso de Uso é uma notação que objetiva representar visualmente as funcionalidades de um sistema, obtidas através das descrições textuais destas funcionalidades (casos de uso) do ponto de vista do usuário. Neste modelo, as funcionalidades do sistema são representadas por casos de uso que são associados a atores. Atores são agentes que representam entidades externas que interagem com o sistema (pessoas ou outros sistemas) [Booch e Rumbaugh 2006]. A Figura 4 apresenta um modelo parcial do Diagrama de Casos de Uso para o domínio aplicado. 


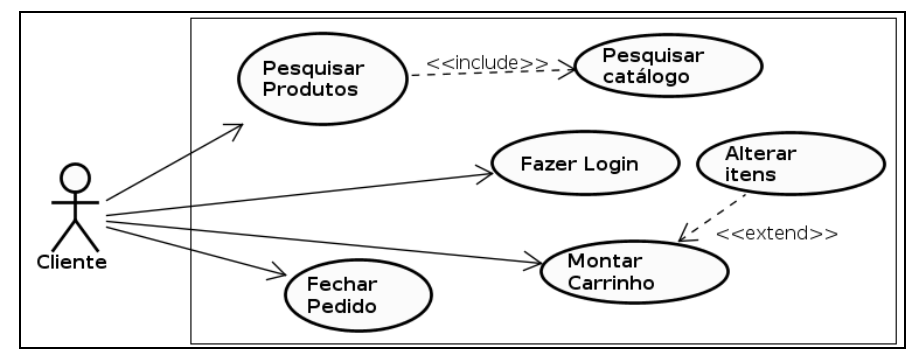

Figura 4. Diagrama de Casos de Uso o domínio do comércio eletrônico (adaptado de Albuquerque et al, 2014a)

Uma Estória do Usuário (User Story - US) é uma descrição simples de uma funcionalidade requerida pelo usuário, que deverá ser atendida pelo proejto a ser desenvolvido [Cohn 2004]. As USs são usadas em alguns processos de desenvolvimento ágil, e são consideradas artefatos de grande importância para serem usadas no planejamento do produto a se desenvolver [Jaqueira et al 2013]. Visualmente, não existe um modelo próprio para representação das USs. Um modelo deste tipo de cartão é proposto por Ambler (2003). A Figura 5 apresenta um levantamento parcial de US para o domínio do comércio eletrônico.

\begin{tabular}{l} 
ID: 01 \\
$\begin{array}{l}\text { Como cliente, eu quero pesquisar } \\
\text { os produtos, para adicioná-los ao } \\
\text { meu pedido. }\end{array}$ \\
\hline [Observações]
\end{tabular}

\begin{tabular}{l} 
ID: $\mathbf{0 2}$ \\
\hline $\begin{array}{l}\text { Como cliente, eu quero visualizar } \\
\text { deta-lhes do produto para } \\
\text { adicionar o pedido. }\end{array}$ \\
\hline [Observações]
\end{tabular}

\begin{tabular}{l} 
ID: $\mathbf{0 3}$ \\
\hline Como cliente, eu quero ter \\
informações atualizadas dos \\
produtos para conhecer as \\
condições da oferta. \\
\hline [Observações]
\end{tabular}

Figura 5. Levantamento de US para o domínio do comércio eletrônico.

A seguir, serão aplicadas as fases de execução da proposta do GenNormas para o domínio do e-Commerce, e as propostas de adaptações para as linguagens:

- [Fase1::Etapa1] Requisitos dos Stakeholders: para o exemplo do e-Commerce, os modelos de especificação dos requisitos levantados para o domínio da aplicação são demonstrados na Figura 3 (em BPMN), na Figura 4 (em Diagrama de Casos de Uso) e na Figura 5 (em User Story).

- [Fase1::Etapa2] Elicitação de Normas ou Leis: a representação visual do modelo de dependência legal permanece a mesma definida no Nòmos para o domínio de comércio eletrônico, apresentada na Figura $1 b$.

- [Fase2::Etapa1] Personificação de Sujeitos Legais: propomos as seguintes representações: (i) para a Notação BPMN, adição textual na região correspondente ao nome da piscina/raia relacionada ao ator que personifica o sujeito legal (Figura 6a); (ii) em Diagramas de Caso de Uso, o uso generalização entre atores externos (Figura 6b); se, pela exigência legal, o próprio sistema personificar uma entidade externa, sugerimos o uso do elemento "pacote" rotulado (Figura 6c); (iii) em US, o destaque da personificação na seção de observações (Figura 6d) para atores externos. Análogo ao Caso de Uso, propomos a utilização do modelo Legal Conformancy Story - LCS, para personificação de entidades externas pelo sistema, destacando a personificação na seção de observações (Figura 6e). 
- [Fase2::Etapa2] Busca por Realizações: uma vez representados os sujeitos legais, destacam-se as realizações para as NPs: (i) para BPMN, propõe-se a utilização do elemento "grupo" da notação, rotulado com a NP realizada (Figura 7a). Caso seja necessário o refinamento de algum elemento, estes devem ser colocados em subprocessos, também rotulados; (ii) em Diagramas de Caso de Uso, a utilização de um estereótipo com a NP realizada dentro do caso de uso (Figura 7b). Se houverem refinamentos, estes devem ser agrupados em "pacotes" nomeados com a NP realizada; (iii) em US, indicamos o uso do termo "Realize: $\langle N P x\rangle$ " (Figura 7c).

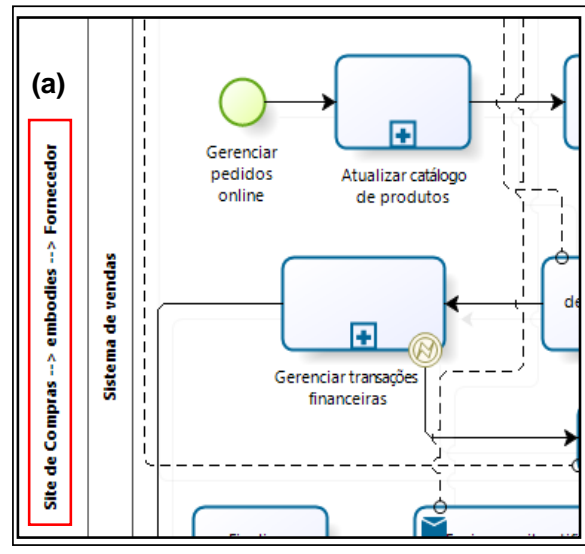

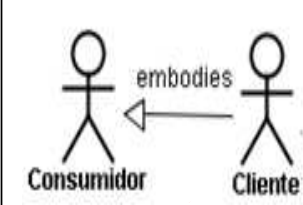

(b)

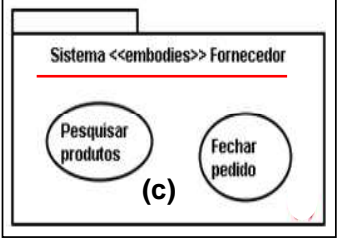

Figura 6. Relações de Personificação

- [Fase2::Etapa 3] Operacionalização de Realizações: (i) em BPMN o comportamento do processo/sistema é expresso diretamente por tarefas, eventos, etc.. Como estes elementos de baixo nível devem ter passado pelos refinamentos necessários para a realização das NPs, esta etapa de operacionalização não foi utilizada; (ii) no Diagrama de Caso de Uso, propomos que a realização desta etapa deve ser feita pelo Detalhamento dos Casos de Uso; (iii) nas USs e nos modelos LCS, estão descritos tanto os objetivos do stakeholders, como as ações que operacionalizam estes objetivos. Desta forma, esta tarefa já foi cumprida.



(a)
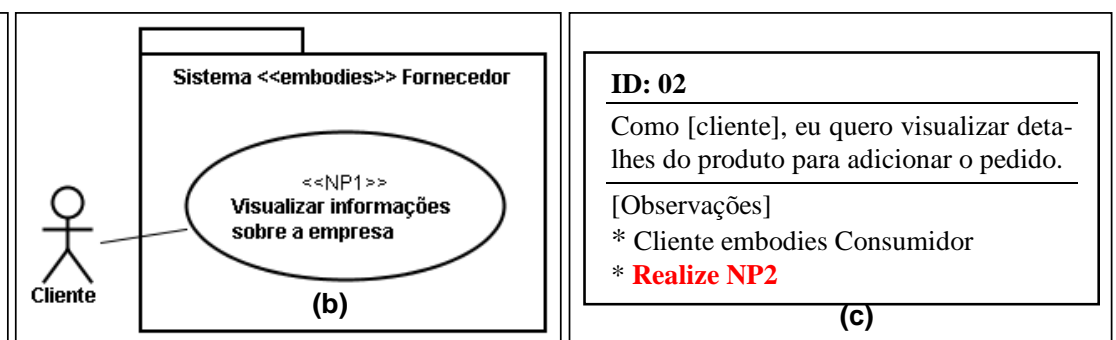

Figura 7. Relações de Realização

- [Fase 2::Etapa4] Identificação de Artefatos de Prova: (i) em BPMN, propomos a identificação de objetos de dados rotulados com $\langle\langle A P\rangle\rangle$, seguido da sua descrição dentro do processo, ligados às tarefas. Se não existirem, deverão ser criados (Figura 8a); (ii) para os Diagramas de Casos de Uso, sugerimos a utilização de anotações com o mesmo estereótipo, ligada ao caso de uso correspondente (Figura 8b); (iii) em USs, indicamos que nos elementos que realizam as NPs que podem gerar artefatos de prova, seja incluído o estereótipo no campo de observações (Figura 8c). 
- [Fase 3]: Verificação da Conformidade: como esta fase se detêm sobre a validação da documentação gerada, ela não foi alterada. Ao final da aplicação do processo, se todos os artefatos estiverem de acordo com os modelos propostos, os requisitos forem aceitos e estiverem sob a conformidade legal, o processo é finalizado.

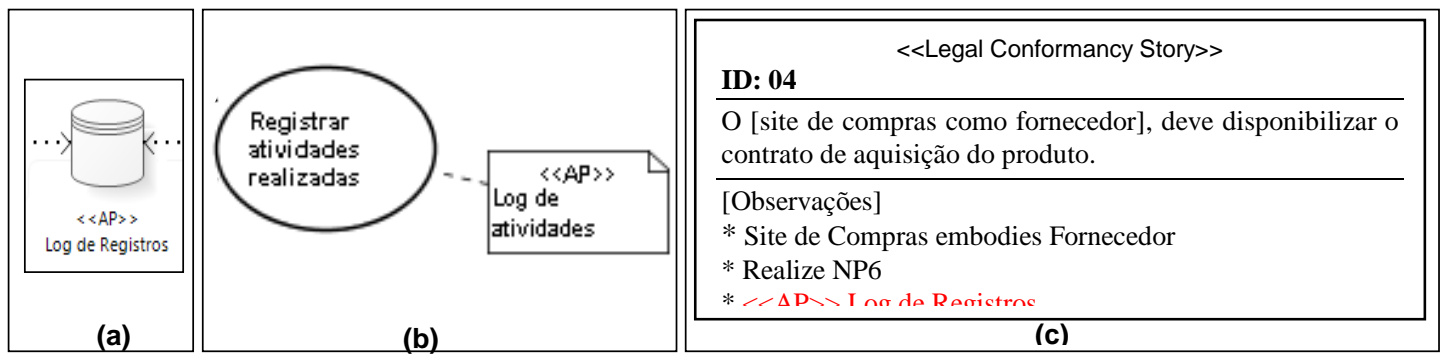

Figura 8. Identificação de Artefatos de Prova

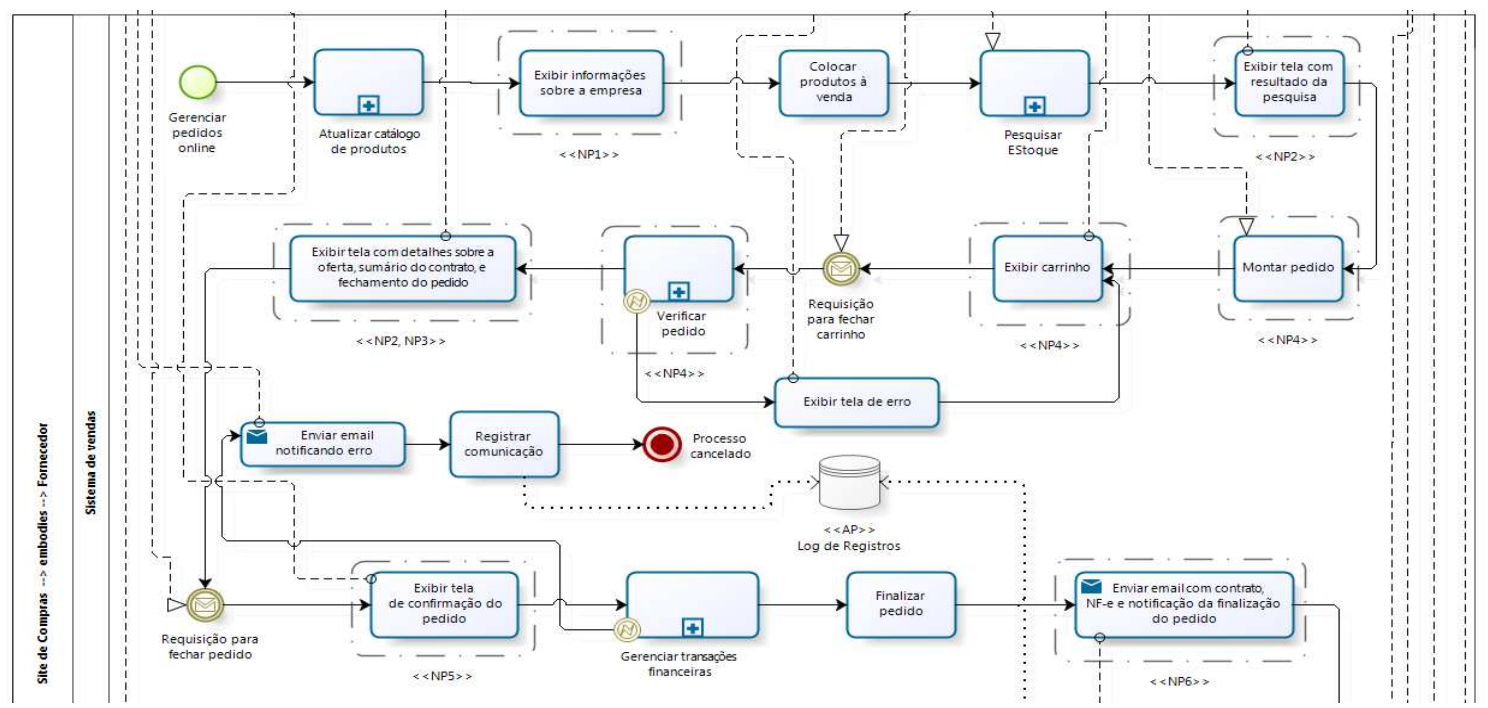

Figura 9. Modelo parcial de Requisitos de Conformidade, em BPMN

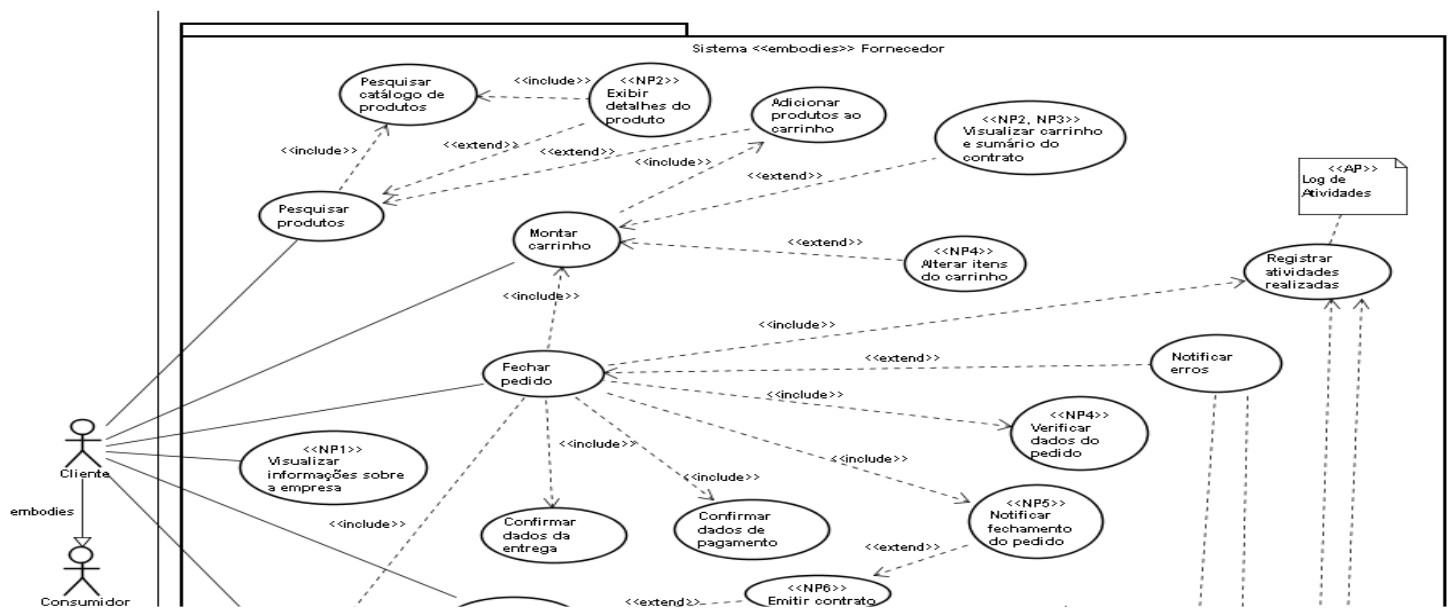

Figura 10. Modelo parcial de Requisitos de Conformidade, em Diagramas de Caso de Uso 
Ao final desta etapa, um Modelo Final de Requisitos de Conformidade deve ser gerado. Os modelos parciais finais gerados em BPMN, Diagrama de Casos de Uso e User Story são demonstrados nas Figuras 9, Figura 10 e Figura 11, respectivamente.

\begin{tabular}{|c|c|}
\hline ID: 05 & $<<$ Legal Conformance Story >> \\
\hline \multirow[t]{2}{*}{$\begin{array}{l}\text { Como [cliente], eu quero } \\
\text { visualizar meu carrinho, para } \\
\text { conhecer as condições da oferta e } \\
\text { verificação de erros. }\end{array}$} & $\begin{array}{l}\text { O [site de compras como fornecedor], deve emitir } \\
\text { contrato completo de especificação de compra, } \\
\text { para cumprimento de exigência legal. }\end{array}$ \\
\hline & [Observações] \\
\hline $\begin{array}{l}\text { [Observações] } \\
* \text { Cliente embodies Consumidor. } \\
* \text { Realize: NP2. NP4. }\end{array}$ & $\begin{array}{l}\text { * Site de Compras embodies Fornecedor } \\
\text { * Realize: NP2 } \\
*<<\text { AP }>\text { Log de Resgistros }\end{array}$ \\
\hline
\end{tabular}

Figura 11. Modelo parcial de Requisitos de Conformidade, em User Story

\section{Conclusão e Trabalhos Futuros}

A principal contribuição deste trabalho é a proposta do GenNormas, uma adaptação para a utilização do framework Nòmos [Siena 2010], independentemente de linguagem de especificação de requisitos, para obter conformidade legal na Engenharia de Requisitos, aplicável também à Modelagem de Processos de Negócios. O processo GenNormas envolve atividades de levantamento de requisitos com os stakeholders, o levantamento e a modelagem de leis relacionadas ao domínio, diretrizes de refinamento dos requisitos, e uma etapa de validação da conformidade legal dos requisitos.

Uma segunda contribuição é a aplicação do framework Nòmos a um sistema no domínio de comércio eletrônico, considerando a legislação brasileira. Como resultado, obteve-se a modelagem da lei do comércio eletrônico da forma de Relações de Dependência Legal do Nòmos.

A terceira contribuição foi a aplicação do processo GenNormas a modelos de especificação aceitos na indústria, como a Notação para Modelagem de Processos de Negócio (BPMN), os Diagramas de Caso de Uso e a técnica ágil de User Story, para ilustrar a sua flexibilidade em relação a linguagem de modelagem de requisitos. Para os modelos utilizados, também foram sugeridas algumas diretrizes e extensões para a representação e comprovação da conformidade legal. Pela ampla utilização dessas linguagens na indústria, cremos que o GenNormas terá mais facilidade para ser adotado.

Como pretendemos que o processo proposto seja adotado na indústria, futuramente ele deve ser aplicado em casos reais de desenvolvimento de software e modelagem de processos de negócios. Além disso, é preciso aplicar o GenNormas a outras linguagens de modelagem de requisitos para elencar possíveis fragilidades e melhoras no processo.

Do ponto de vista das discussões existentes entre os stakeholders para chegar a um consenso sobre a aceitabilidade dos requisitos, serão estudadas o uso de técnicas automatizadas ou híbridas, para orientar a seleção e discussão do conteúdo legal, como a análise da aceitabilidade de requisitos legais, agregando valor à nossa proposta.

Além do exposto, o acompanhamento das evoluções dos requisitos e das leis e seu impacto no projeto desenvolvido é outra vertente que pode ser trabalhada. 
Principalmente, a alteração no entendimento ou o surgimento de outras leis que prescrevam leis já realizadas, pode ter grande impacto no processo. Assim, é preciso desenvolver técnicas de rastreabilidade que permitam documentar, visualizar e analisar o impacto proporcionado por estas mudanças no sistema ou no processo.

\section{Referências}

Albuquerque, H.O., Silva, C., Silva, D. R. D (2014a). GenNòmos: um processo genérico para utilização do framework Nòmos. In: X Simpósio Brasileiro de Sistemas de Informação, Londrina-PR.

Albuquerque, H.O., Silva, C., Silva, D. R. D (2014b). NòmosBPMN: Adaptando o Nòmos para a Modelagem de Processos de Negócio. In: CibSE 2014, XVII Congresso Ibero-Americano em Engenharia de Software, Pucón, Chile.

Ambler, S.W. (2013). User Stories: An Agile Introduction.. Disponível em http://www.agilemodeling.com/artifacts/userStory.htm\#Figure3.

Booch, G., Rumbaugh, J (2006). UML: guia do usuário. Campus: Rio de Janeiro.

Brasil (2013). Decreto-Lei n. ${ }^{\circ}$ 4.567, de 4 de setembro de 1942. Lei de Introdução às normas do Direito Brasileiro. Diário Oficial da República Federativa do Brasil. Brasília, DF.

Brasil (1990). Decreto n. ${ }^{\circ}$ 7.962, de 15 de março de 2013. Regulamenta a Lei n. ${ }^{\circ}$ 8.078, de 11 de setembro de 1990, para dispor sob a contratação do comércio eletrônico. Diário Oficial da República Federativa do Brasil. Brasília, DF, n. 51, p. 01, 15 mar., 2013. Seção 1, Ed. Extra.

Carvallo, J. P., Franch, X. (2014). Lessons Learned in the Use of i* by Non-Technical Users. Proceedings of the Seventh International $i^{*}$ Workshop co-located with the 26th International Conference on Advanced Information Systems Engineering (CAiSE 2014), Thessaloniki, Greece.

Cohn, M. (2004). User Stories Applied: For Agile Software Development (The Addison-Wesley Signature Series), March. Addison-Wesley Professional, Reading.

E-Bit/Buscapé (2016). Avaliação 360 do Comércio Eletrônico em 2015. Disponível em http://img.ebit.com.br/webshoppers/pdf/33_webshoppers.pdf.

Ghanavati., S (2013). Legal-URN Framework for Legal Compliance of Business Processes. PhD Thesis.

Gordon, D., Breaux, T. (2011), Comparing Requirements from Multiple Jurisdictions. In: 2011 Fourth International Workshop on Requirements Engineering and Law (RELAW 2011).

Governatori, G (2010). Law, Logic and Business Processes. In: Third International Workshop on Requirements Engineering and Law (RELAW).

Hohfeld. W. (1913). Some Fundamental Legal Conceptions as Applied in Judicial Reasoning. Yale Law Journal 23. 
Ingolfo, S., Siena, A., Mylopoulos, J (2014). Goals and Compliance in Nòmos 3. In: Proceedings of the Seventh International i* Workshop, 26th International Conference on Advanced Information Systems Engineering (CAiSE 2014).

Ingolfo, S. et al (2013). Arguing regulatory compliance of software requirements. In: Data \& Knowledge Engineering.

Jaqueira, A., Lucena, M., Aranha, E., Alencar, F., Castro, J. (2013). Using i* Models to Enrich User Stories. In: Proceedings of the 6th International i* Workshop (iStar 2013).

Lustosa, Oton (2001). A lei, o costume, o Direito. Revista Jus Navigandi, Teresina-PI, ano 6, n. 51.

Miranda Rosa. Apud João Baptista Herkennhoff (1993). Direito e Utopia. Editora Acadêmica, p. 20.

OMG (2011). Unified Modeling Language (UML): $\quad$ Superstructure. http://www.uml.org/.

OMG (2010). Business Process Modeling Notation Specification. http://www.bpmn.org.

Sampaio, M.; Hildsorf, W.C. (2012). Logística Reversa no Comércio Eletrônico: um estudo de caso. In: XXXII Encontro Nacional de Engenharia de Produção.

Schleicher, D., Leymann, F., Weidmann, M (2010).. Compliance Scopes: Extending the BPMN 2.0 Meta Model to Specify Compliance Requirements. IEEE International Conference on Service-Oriented Computing and Applications (SOCA).

Siena, A. (2010). Engineering Law-Compliant Requirements. The Nòmos Framework. $\mathrm{Ph}$.D. thesis. University of Trento, Italy.

Visa (2014). Relatório e-Readiness, América Latina. Disponível em http://promociones.visa.com/lac/ecommerce/pt/index.html .

Yu, E., Gunter, D.A., Franch, X., Castro, J. (2013). Practical Applications of $i^{*}$ in Industry: The State of the Art. In: 21st IEEE International Requirements Engineering Conference (RE).

Yu, E. (1995). Modelling Strategic Relationships for Business Process Reengineering, Ph.D Thesis, Dept. of Computer Science, University of Toronto. 